\title{
DISCURSO DE PARANINFADO $\left(^{*}\right)$
}

\section{ALBAXYo WoISKI}

\section{Meus afilhados:}

Minha presenca nesta tribuna, no momentc em que vos despedis da vida acadêmica, com os vossos pensamentos plenos de saudade dos dias que transcorreram e de esperança nos que hāo de vir, decorre de um único imperativo - a vossa vontade - escolhendo-me para vosso paraninfo.

Esse vosso convite, para mim muito honroso, só posso atribuir aos vossos sentimentos de amizade ao mestre com quem convivestes.

Agradeço pelos conceitos há pouco emitidos a meu respeito pelo vosso talentoso representante. Digo-vos, porém, que se êle não traduziu a realidade, teve o mérito de trazer à tona a generosidade do vosso coração bem formado.

Durante o tempo em que juntos palmilhamos os mesmos ásperos caminhos do estudo refletido, enquanto acompanháveis as preleçōes de quem tinha o maior interêsse em vos iniciar na Arte de Ensinar a ensinar, a mais difícil das artes, em virtude do pêso e do número dos valores que entram em jôgo, pude observar o quanto estáveis preocupadcs com a problemática da Educação e do Ensino.

Grande foi minha alegria ao perceber a vossa decisão, que se ia tornando imperativa com o aprefundar as questōes, de vos tornardes professôres mais eficientes porque mais esclarecidos.

No decorrer das horas em que procuramos compreender a diferença palmar existente entre a instrução e a educação, aprendestes que educar é problema teleológico pcrque humanístico, enquanto que a instrução, por ser problema viário, é questão técnica.

(•) - Colação de grau dos licenciados de 1960, da Fac. de Filosofía da U. do PR. 
Ouvindo-me, verificastes como a Arte de Educar possuindo valores inúmeros da paternidade, não pode admitir o ensino como simples reação química ou reflexo nervoso-cerebral.

Compreendestes assim, como é faisa a atitude assumida por certos educadnres modernos, hipnotizados pelo brilho fácil e fugaz das novidades, que com incrível convicção, vêm transformando a Pedagogia contemporânea em simples campo de pesquisas metodológicas, pouco lhes importando o valor humano dos alunos, contanto que as reaçóes acabem por confirmar as suas hipóteses. Após haverem destituído a educação de qualquer: finalidade extrínseca, após haverem despojado a educação de ideais superiores, estão êles, quais iconoclastas da era do arranha-céu, a mutilar a própria realidade pedagógica, reduzindo a Escola a mero laboratório e a Educação a fórmulas frias porque científicas. Embalados pelo tecnicismo pedagógico, querem, à fôrça, construir a Educação pelo tecnicismo pedagógico, querem, à fôrça, construir a Educação com independência absoluta dos valores metafísicos, morais e religiosos.

Coube a mim a difícil tarefa de vos ministrar ensinamentos relativos à Didática, frondoso ramo praxológico da Pedagogia, cujo objeto é o ensino dirigido por técnicas humanizadas. Ensinei-vos, assim, que a complexa Arte de ensinar a aprender, parte de uma decisão, avolıma-se numa justificação e realiza-se numa ação. Pudestes perceber que existe, na formaçäo do moderno professor, três estudos básicos conhecidos como a Sistemática, a Matética e a Metódica, de tal modo entrelaçados que não valem isolados. Na Sistemática, estudastes os valores teleológicos da vossa profissão. $\mathrm{Na} \mathrm{Ma-}$ tética, percebestes os valores ontológicos da Educação, e na Metódica, conseguistes avaliar os valores técnicos do ensino.

Com isto queremos dizer que a Pedagogia possuindo dois aspectos, um abstrato e outro concreto, cabe à Didática realizar de modo racional e econômico os ideais humanos.

Das nossas conversas vistes que, antes de realizar, há sempre necessidade de idealizar. Nesse ponto, pudestes perceber que é no solo fecundo porém ondulante da Filosofia que se 
ancora a Pedagogia, bem como é no campo das Bases e Diretrizes que se travam as maiores batalhas educacionais.

Conhecestes, assim, as várias teorias filosóficas que vêm influindo, qual fermento, na educação. estruturando-a ou deformando-a.

Pudemos, durante nossas aulas, criticar o Naturalismo de Rousseau, que negando a ordem sobrenatural e sua influência na educação, desconhece os traços que o pecado original deixou na natureza humana, pois sustenta que o Homem é naturalmente bom. Tão poucc aceita a graça divina, os sacramentos e os outros meios sobrenaturais na educação. A Religião é alheia à Pedagogia, e seus partidários são pelo laxismo escolar.

Estudastes o Materialismo, sorrateiramente pregado pela Psicologia Sem Alma, o qual nega a existência do espírito e portanto de um Deus pessoal e da alma humana. O homem, afirmam os seus defensores, não se diterencia essencialmente dos animais, porque a sua alma é igual a dêles, embora um pouco mais aperfeiçoada. A educação do homem pode assim, guiar-se em muitas facêtas, pela vida que se dá aos animais superiores, não sòmente na aprendizagem, mas, também, na formação da vonts̊de, que não difere muito dos instintos dos animais, já que nào há verdadeira liberdade nem existe consciência moral.

Aprendestes que, os seguidores do Nacionalismo exagerado, torcendo as idéias platônicas a respeito do poder estatal, apontam a Nação como fim exclusivo do Homem. A Educação, portanto, tem como único objetivo, preparar o Homem para o bem da Nação, sem reconhecer-lhe a finalidade pessoal que êle deve realizar na vida presente e na preparação para a eternidade. Donde, o direito exclusivo à educação pertencer à Nação, não aos pais de família, nem à Igreja. Defendem, portanto, o monopólio estatal em matéria educativa, como fazem todos os partidários do Estado Totalitário, declarado ou mascarado.

Conhecestes como o Racismo, defendendo que a raça dos povos superiores é o único valor permanente e eterno, numa 
revivescência panteística, exige que a criança seja educada para 0 bem exclusivo dessa raça superior. Donde haver dois tipos de educação: a da raça superior, representada pelo sangue ou pela côr da pele, possuidora de todos os direitos e cujo destino é governar os demais povos e a das raças inferiores cujo destino é ùnicamente servir à raça superior. O Govêrno, poder divino e órgão político-social dessa raça superior é o único que tem o direito de dar educação, como afirmaram Nietzsche e Rosenberg.

Vistes como, dentro da ideologia Socialista, o fim essencial do homem e o bem da sociedade, residindo no aperfeiçoamento social do indivíduo. A educação deve ser encarada sòmente no que fôr útil à sociedade, já que o homem não passa de puro e simples produto do meio em que vive, nada mais é que mero joguete das fôrças coletivas, não tem finalidade pessoal a realizar, nem nesta vida nem na eternidade. Êsse é o objetivo a que deve visar a educação organizada exclusivamente pelo Estado, considerado como o órgão central por excelência de tôdas as questões pertinentes à Educação. Na educação não devem intervir nem a Família, nem a Religião, pois o ensino só tem valor se fôr útil e só será útil se fôr leigo, como ensina John Dewey, dentro do seu Pragmatismo Funcional.

Percebestes como o Comunismo, nascido do cérebro de Marx e de Engels, é teoria extrema do Socialismo utópico que defende não haver valores humanos espirituais. Só existem valores materiais cuja base é a Economia. O fundamento da Economia é o Trabalho, erigido à dignidade divina e dirigido pelo Estado. A Humanidade rege-se por leis econômicas imutáveis que nada devem à Moral e que a levarão, num fatalismo histórico-político, através de diversas etapas, até o estado final da produção socializada e do estabelecimento de uma só classe social, a dos trabalhadores, com a supressão absoluta de tôdas as outras classes sociais. Ensinam os comunistas que é dever de todos acelerar a consecução desta síntese econômico-social por todos os meios, incluindo os violentos e os subversivos. E o que busca, mundialmente, a Ditadura do Proletariado implantada pelo terror na Rússia Soviética e em seus satélites econômico-políticos. A única educação deve ser dada nessa conformidade por meio da Escola do Trabalho, que 
prepara as crianças para o ódio das classes e os jovens para a luta social pelo triunfo do proletariado ateu. Essa educação deve ser dirigida totalmente pelo Estado Comunista, não devendo existir nenhum outro tipo de educação senão o técnico-político.

Estudastes como o Enciclopedismo, nascido do intelectualismo e das teorias racionalistas, pondo a ênfase da educação na aquisição de múltiplos conhecimentos, sobretudo de caráter científico, descuida da formação dos hábitos intelectuais e do espírito de reflexão e de crítica, aprecia mais a quantidade que a qualidade dos conhecimentos, deixa de lado, quase que por completo, a formação da vontade e do caráter, a integração da personalidade e o ajustamento social e emocional da criança.

Concluístes das pesquisas realizadas que o panorama pedagógico atual se apresenta, a quem o contempla do alto, como uma grande babel, onde sistemas, educadores e metodologias, na maior parte das vêzes antagônicas, medem fôrças pela própria sobrevivência, pouco lhes importando o valor humano como tal. Assim é que a síntese pedagógica do momento procura realização dentro do Tradicionalismo e do Escolanovismo.

Ensinei-vos que a Tradição não significa, em Educação, coisa passada e inútil, e a Escola Nova não representa a quintessência da educação. Repetindo Emile Planchard, disse-vos que a "Pedagogia deve ser prudentemente progressiva e que muito do realizado hoje estava latente nos escritos antigos".

Com efeito, a Escola Integral, enriquecida pelos progressos moảernos, defende hoje o desenvolvimento harmonioso de tôdas as qualidades humanas. A formação da razão e da vontade. A integração do caráter e da personalidade. $O$ ajuste emocional e social. A criação dos hábitos bons e o adequado desenvolvimento físico. No terreno intelectual, busca não sòmente dar uma base sólida de conhecimentos, mas, também, formar a capacidade de pensar e julgar, e o desenvolvimento das aptidões estéticas por meio da formação humanística. Defende, porém, que o Homem tem um fim social e nacional, mas, também, deve buscar o seu aperfeiçoamento individual e 
pessoal na vida presente, como meio de adquirir a felicidade eterna. Observa o estado atual da natureza humana, manchada pelo pecado de origem, e a necessidade, portanto, de auxílios sobrenaturais, da doutrina revelada nas Escrituras, da graça divina e dos sacramentos. Reconhece que o direito primário à educação corresponde à Família e o direito sobrenatural à Igreja, cabendo ao Estado um direito secundário e suplementar.

No tocante ac Escolanovismo, aprendestes que a Escola Nova, com os nomes de Escola Ativa, Escola do Trabalho, Escola Funcional, não pode de forma alguma arrogar-se o direito de uma condenação global e sistemática de qualquer outro método educacional especialmente a Escola Tradicional Cristã.

Escola Nova, a par das novidades que sempre atraem e agradam, é também uma tentativa a mais, não há dúvida que com boas bases científicas, mas, mesmo assim, não passa de uma busca de soluções novas para o velho problema da despotencialização das virtudes humanas.

Pudestes perceber que várias das suas conquistas enriqueceram com novas luzes a Pedagogia contemporânea. Mas, percebestes como é apressado considerá-la como a última palavra em matéria de educação. Cem anos não é perspectiva suficiente para conferir-lhe o caráter definitivo de que parece querer revestir-se em mãos de inovadores de todo o momento.

Na realidade, das nossas discussões, pudestes concluir que a Escola Nova, apesar dos avanços que deu à Pedagogia, ainda não constitui a Pedagogia Absoluta, mas, simplesmente é uma contribuição a mais que nos pode conduzir a ela. Realmente, a Escola Nova, apesar das retumbâncias da propaganda, peca veladamente, mas peea, contra um dos axiomas da Pedagogia Perene: a educação integral, precisamente quando dá demasiada ênfase às atividades externas, na maioria das vêzes puramente mecânicas e quantitativas, em prejuízo da atividade intelectual e volitiva, específica do Homem.

A Escola Nova, nascida da observação, não passa de um sistema hipotético, cuja experimentação já tem por vêzes fracassado no campo real, como pudestes perceber nas pesquisas 
realizadas durante o vosso curso acadêmico, sôbre a delinqüência na adolescência atual. Espantou-vos o crescimento da criminalidade infanto-juvenil no mundo iodo, apesar do crescimento, no mundo todo também, dos laboratórios de pesquisas pedagógicas donde surgem tantas fórmulas mágicas para a nova educação.

A Escola Nova, mostrei-vos, engendra certo disfarçado desprêzo pela autoridade e pela ação do educador junto ao educando, sob o pretexto científico de que a educação deve partir exclusivamente do educando e de suas necessidades psicológico-sociais. Educador passou, de certa forma, a plano inferior ao dos meios auxiliares do ensino moderno.

Demonstrei-vos que a Escola Nova não pode chamar-se completamente original, pois, em vários aspectos, nada mais é que uma exacerbação e mesmo exagêro de certas práticas de algumas escolas tradicionais. Mostrei-vos, também, como na Escola Nova sente-se muito ao de leve ou a hesitação em definir-se por um ideal educacional ou a completa indiferença quanto ao mesmo, chegando até alguns inovadores a afirmar que a educação não tem outro fim senão ativar-se a si mesma!...

Verificastes, por vós mesmos, que não o esfôrço isolado dêste ou daquele século, desta ou daquela teoria, dêste ou daquele método, que dará solução satisfatória ao magno problema de todos os tempos - a Educação.

Problema com perspectivas eternas, a educação será preocupação constante dos homens de tôdas as épocas. Se considerarmos a vida humana como possuindo duas partes integradas - uma temporal e outra eterna - estaremos dando solução falsa, porque parcial, à educação, ao preparar o Homem para enfrentar os embates da primeira etapa da jornada somente. E como as duas partes da sua vida se entrelaçam de maneira íntima, tal solução pela metade terá inevitàvelmente reflexo sôbre a diretriz dada à etapa terrestre da vida. Aprendestes que não pode haver solução certa para o problema educacional sem o estabelecimento de um ideal assentado para a vida humana. Essa falha de ideal que se nota 
em certos arraiais da Escola Nova, não lhe é própria, mas da Filosofia Moderna, onde se estriba a moderna educação.

E justamente o que falta aos pensadores modernos é êsse esfôrço para buscar e para amar com sinceridade a Verdade, - Caminho e a Vida, amor êsse que não se deixa obscurecer pelos obstáculos intelectuais nem pelos obstáculos morais do orgulho, da avareza e da sensualidade, característicos marcantes do Século da Técnica, do Dinheiro e do Sexo.

Por isso mesmo, percebestes como a insatisfação e a insegurança serão, ainda por muito tempo, o sinal que estigmatizará tôdas as tentativas educacionais, enquanto os educadores modernos não se lembrarem que, acima do ar intoxicado e suicida do pensamento moderno, revoltado contra os preceitos divinos e por isso mesmo voltado para a fugacidade da matéria, paira liviemente um problema de maior amplitude e transcendência que qualquer problema politico: o problema do Homem e sua felicidade eterna.

Porém, caros colegas, quando vos dizíamos que sem antes darmos solução aos problemas éticos da educação, inútil e vã é tôda e qualquer técnica educativa, por mais adornada de nomes exóticos e pomposos com que se apresente, não estávamos negando, e disso sois testemunhas, que as técnicas educativas sejam inutilidades, bastando terdes ideal e desejos.

Pelo contrário, aprendestes que a Didática vem a ser precisamente a Arte de dirigir tècnicamente a aprendizagem escolar.

Sem técnica educativa, realmente, estéril é todo e qualquer ideal educacional.

No decorrer das nossas aulas dizia-vos eu que a vossa técnica no ensinar é o vosso cartão de visita profissional, e nisso deveis distinguir-vos dos auto-didatas do magistério.

Sois professôres modernos justamente porque ireis realizar velhos ideais por meio de processos novos.

Hoje fôstes investidos da dignidade não somente de Missionários da Cultura, mas também acabais de receber o diploma da habilitação técnica do magistério. Isso quer dizer que de hoje em diante deveis viver a vida do ciclo docente. 
Percebestes que o ciclo docente é tôda uma série de atividades exercidas em sucessão pelo professor moderno, para dirigir e orientai tècnicamente o complicado processo da aprendizagem escolar rumo ao objetivo concreto do ensino, que é saber fazer.

Estudastes o ciclo docente em suas três fases básicas: o planejamento do ensino, a sua execução e o seu contrôle. Compreendestes assim que o planejamento, desdobrando-se em três planos, apóia-se na Legislação Oficial do Ensino, mas contém o plano de curso, para o período letivo, o plano de unidade, para a disciplina, e o plano de aula, para a execução do ensino.

Percebestes que a execução do ensino, que é subsidiada por conhecimentos de psicologia, biologia e sociologia educacional, exige, por parte do professor moderno, motivação pedagógica, apresentação dosada da matéria, direção das atividades discentes para permitir a participção dos alunos, técnicas de integração e de fixação dos conteúdos da aprendizagem, que irão formar os hábitos e os automatismos necessários.

Por fim compreendestes que o ensino educativo sendo para a Vida e não para a Escola, necessita ser controlado. $O$ contrôle da aprendizagem comporta a sondagem, o manejo de classe e o uso da disciplina, a retificação, a verificação e a avaliação dos resultados.

Aprendestes assim que a vida do professor moderno consiste mais em dar que em tirar e que, quando o professor, convicto da sua tarefa de diretor da aprendizag=m dosar a sua atividade escolar de acôrdo com a seqüência natural dessas fases, terá já uma garantia de sucesso na sua carreira, principalmente se condimentar com muita afeição aos alunos e muito amor à sua disciplina, deixando de ser um aventureiro, um inábil repetidor de livros, atirando-se sem rumo em tarefa de tamanho vulto, para ser um esclarecido burilador de valores humanos. Será um mestre no verdadeiro sentido da palavra, porque planejando, enxergará com clareza e agirá com eficácia, acompanhando metòdicamente o aluno no ritmo vital da aprendizagem. Orientará, motivará. estimulará 
os interêsses do aluno sem esquecer-lhe os valores sociológicos, biológicos e psicológicos.

E o ciclo docente que vos oferece a técnica para colimardes os objetivos visados e exigidos pela missão da Fscola e pela ética profissional dos professôres: cultivar, exercitar, desenvolver, fortificar, polir tôdas as faculdades que constituem a natureza e a dignidade humana.

Acabastes de jurar fidelidade à causa da Educação! Nesse momento solene, diante de vossos pais, parentes, amigos, autoridades, recebestes um título universitário, infelizmente não bem conhecido entre nós no Brasil. Refiro-me ao título de Licenciado. Possuís agora dois graus universitários: o de Bacharel e o de Licenciado. Por essa razão, permitam-me dizer ao público aqui presente que não sois simples professor. Sois, de agora em diante, professor especializado do ensino secundário brasileiro. Fôstes incluídos na categoria de profissionais do ensino especializado.

E necessário que façais valer o vosso título dentro da vastidão dos nossos $8.500 .000 \mathrm{k}^{2}$ de território, não pela violência mas pela eficiência.

Realmente, parece que se esboça no mundo atual uma "consciência profissional do magistério", como afirma Kandell, da Universidade de Colúmbia. Ensina êle que "o professor vem-se tornando um profissional e o magistério já vem merecendo as honras de profissão". "A profissão do professor já não é mais considerada como uma "mecânica" de transmissão de partes do currículo escolar". "Hoje, há, continua o eminente mestre, uma transferência da ênfase do ensino da matéria para outro valor: o aluno. Isso significa, conclui, uma transferência real para outra ênfase: o professor como condutor de personalidades. numa civilização em mudança". Por essa razão hoje se exige que o professor, mesmo primário, possua estudos superiores na sua formação cultural e técnica.

Aqui reside o valor das Faculdades de Filosofia, Ciências e Letras. Já é tempo que se saiba que uma Faculdade de Filosofia, não uma simples Escola Normal Supericr. O Licenciado é na realidade um professor secundário de valor universitário. 
Licenciado, têrmo que precisa ser divulgado para ser reconhecido pelo público e até pelas autoridades legislativas do Pais, é assim o grau universitário conferido solenemente aos professôres que se especializaram não sòmente em sua disciplina, mas, também, na técnica de transmiti-la nos moldes da Escola em renovação.

Licenciado, meus senhores e minhas senhoras, é profissão liberal específica do magistério, do mesmo giau universitário da profissão do advogado, do médico, do engenheiro. Já é tempo de irmos deixando de lado razões de ordem sentimental e irmos dando valor ao Licenciado, distinguindo-o do professor, do mesmo modo como se distingue, com muita razão, o advogado do "rábula", o engenheiro do "construtor licenciado", o farmacêutico do "prático", o médico do "curandeiro", o jornalista do "repórter".

$\mathrm{Na}$ realidade. professor qualquer um pode ser. Equestão de vocação ou de gôsto. Licenciado, só cabe como título a vós, caros afilhados, que, como tantos outros desde 1939, vêm cursando regularmente um curso das diversas Faculdades de Filosofia, Ciências e Letras disseminadas por êste vasto Brasil, para conquistar o grau superior do magistério que lhes dá habilitação legal e esfecífica, para o trabalho público ou particular de lecionar matéria da sua especialidade com eficiência didática e idealismo construtor.

Meus caros colegas de hoje e meus alunos de ontem! Todos nós ouvimos o solene juramento prestado há pouco. Temos assim a certeza de que ireis valorizar o título de Licenciado que conquistastes com tanto sacrifício, onde estiverdes e onde trabalhardes.

Dificuldades hão de vir. Não vos atemorize o mundo atual, conturbado por explosões de ódios e violências. Ide e ensinai! E a vossa missão que possui traços do sacerdócio! Alguém precisa sacrificar-se em meio ao confôrto conformista que caracteriza a nossa época!

Quero que minhas últimas palavras sejam a mais viva afirmação do meu sentir, ao desejar-vos, com abundància de alma e coração, que obtenhais brilhantes vitórias na luta que ides empreender contra a ignorância e a incompreensão. 
Todos ansiamos por um "Mundo Melhor". Está em vossas mãos uma parcela dêsse trabalho. Confiai em Deus, amai a adolescência, olhai para a Pátria, aperfeiçoai vossa técnica, e sêde felizes em meio de vossa família e vossos amigos!

Sêde o sal da Cultura e a luz para a mocidade!...

Curitiba, 7 de dezembro de 1960 . 